\title{
Antioxidant and Antibacterial Potential of Silver Nanoparticles: Biogenic Synthesis Utilizing Apple Extract
}

\author{
Upendra Nagaich, Neha Gulati, and Swati Chauhan \\ Department of Pharmaceutics, Amity Institute of Pharmacy, Amity University, Noida, Uttar Pradesh, India \\ Correspondence should be addressed to Swati Chauhan; 91chauhanswati@gmail.com
}

Received 28 July 2016; Revised 26 October 2016; Accepted 31 October 2016

Academic Editor: Amnon Sintov

Copyright ( 2016 Upendra Nagaich et al. This is an open access article distributed under the Creative Commons Attribution License, which permits unrestricted use, distribution, and reproduction in any medium, provided the original work is properly cited.

\begin{abstract}
The advancement of the biological production of nanoparticles using herbal extracts performs a significant role in nanotechnology discipline as it is green and does not engage harsh chemicals. The objective of the present investigation was to extract flavonoids in the mode of apple extract and synthesize its silver nanoparticles and ultimately nanoparticles loading into hydrogels. The presence of flavonoids in apple extract was characterized by preliminary testing like dil. ammonia test and confirmatory test by magnesium ribbon test. The synthesized silver nanoparticles were characterized using UV spectroscopy, particle size and surface morphology, and zeta potential. Silver nanoparticles loaded hydrogels were evaluated for physical appearance, $\mathrm{pH}$, viscosity, spreadability, porosity, in vitro release, ex vivo permeation, and antibacterial (E. coli and S. aureus) and antioxidant studies (DPPH radical scavenging assay). Well dispersed silver nanoparticles below were observed in scanning electron microscope image. Hydrogels displayed in vitro release of $98.01 \% \pm 0.37 \%$ up to $24 \mathrm{~h}$ and ex vivo permeation of $98.81 \pm 0.24 \%$ up to $24 \mathrm{~h}$. Hydrogel effectively inhibited the growth of both microorganism indicating good antibacterial properties. The value of percent radical inhibition was $75.16 \% \pm 0.04$ revealing its high antioxidant properties. As an outcome, it can be concluded that antioxidant and antiageing traits of flavonoids in apple extract plus biocidal feature of silver nanoparticles can be synergistically and successfully utilized in the form of hydrogel.
\end{abstract}

\section{Introduction}

Nanotechnology is an emerging tool as drug delivery system in variety of serious disorders. It is an innovative technique which includes the design, characterization, production, and application of structures, devices, and systems by controlling shape and size at the nanometer scale. It covers the size range of $1 \mathrm{~nm}$ to $100 \mathrm{~nm}$ [1]. Nanoparticles are the materials with the overall size of $100 \mathrm{~nm}$ [2]. Nanoparticles can be classified as polymeric (natural and synthetic), lipoidal (biodegradable), and metal nanoparticles (iron oxide, gold nanoparticles, and silver nanoparticles) [3]. Metal nanoparticles using plant or plant extract are a way ahead towards greener approach for application as drug delivery system. Silver nanoparticles show good anti bacterial properties as silver has been widely used as healing and antibacterial agent for many years [4]. Silver nanoparticles (AgNPs) also possess antifungal, antiinflammatory, antiviral, and antiplatelet activity [5]. Silver nanoparticles can be synthesized by using any of the following methods [6], namely, physical methods, chemical reduction (thermal reduction, polyol process, microemulsion techniques), and photochemical reduction (microwave reduction, photoreduction, and X-ray radiolysis).

Malus domestica (Rosaceae) commonly known as apple is full of high levels of triterpenoids, anthocyanins, and phenolic compounds. Apple polyphenols and oligomeric proanthocyanidins are primarily responsible for its antioxidant activity [7]. Flavonoids, quercetin, and hesperetin present in apple contribute to its antiageing effects [8]. The utilization of natural compounds in protection of skin especially topical application of antioxidants indicates that they usefully decrease skin aging $[9,10]$.

Basically, premature skin ageing is a vast biological phenomenon that mainly occur by the combination of endogenous or intrinsic (genetics, cellular metabolism, hormone, and metabolic processes) and exogenous or extrinsic (chronic 
light exposure, pollution, ionizing radiation, chemicals, and toxins) factors [11]. Photosensitized skin is characterized by dry, rough, pigmented, and abraded skin. This is due to high exposure to direct sunlight [8]. Biological systems are damaged by the presence of free radicals. The responsible free radicals are oxygen free radicals or generally known as reactive oxygen species (ROS) [12].

Studies show that apple decreases the presence of ROS generated by hydrogen peroxide exposure in lymphocytes [13].

In present investigation, we have tried to investigate the synergistic effect of AgNPs and flavonoids in apple extract by loading apple extract AgNPs into hydrogel and characterizing it for antibacterial and antioxidant properties in a unit dose formulation. Apple extract was utilized for the green synthesis of silver nanoparticles via chemical reduction technique. Furthermore Apple extract acts as both reducing and capping agent. Moreover, optimized silver nanoparticles were selected and loaded to hydrogel to deliver actives via topical route for the therapy of premature skin ageing.

\section{Materials and Methods}

2.1. Materials. Malus domestica, family Rosaceae (apple), was purchased from local market. Methanol, formic acid, silver nitrate, carbopol-934, triethanolamine, glycerine, potassium dihydrogen phosphate, sodium hydroxide, 2,2-diphenyl-2picrylhydrazyl hydrate (DPPH), agar, and nutrient medium were purchased from CDH Pvt. Ltd., New Delhi. All solvents used were of analytical grade.

\subsection{Methodology}

2.2.1. Preparation of Apple Extract. Phenolic compounds from apple were extracted using solvent mixture of methanol: formic acid: water in the ratio of $70: 2: 28$. Weighed quantity of freshly cut apple pieces was added to the solution of methanol : formic acid : water (MFW) and homogenized in a blender (Polytron PT 1600E, kinematica AG) for $2 \mathrm{~min}$. The mixture was transferred to a beaker, covered with parafilm, and held for $24 \mathrm{~h}$ at $4^{\circ} \mathrm{C}$. Then the mixture was washed with $20 \mathrm{~mL}$ of MFW. Extract was collected and then evaporated for dryness at $45^{\circ} \mathrm{C}$ under vacuum with a rotary evaporator [14].

2.2.2. Synthesis of Silver Nanoparticles. $1 \mathrm{M}$ silver nitrate solution was prepared by adding $1.699 \mathrm{~g}$ of AgNO3 to $1 \mathrm{~L}$ distilled water. $30 \mathrm{~mL}$ of apple extract was taken in a $100 \mathrm{~mL}$ conical flask. $20 \mathrm{~mL}$ of freshly prepared $0.1 \mathrm{M} \mathrm{AgNO3}$ solution was added (drop-wise) to the flask. The flask was incubated in dark for $24 \mathrm{hrs}$ at room temperature [15].

\subsubsection{Preparation of Apple Extract Loaded Silver Nanoparticles} Based Hydrogel. Apple extract loaded silver nanoparticles were then incorporated into a hydrogel base as given in Table 1. Accurately weighed quantity of carbopol-934 (poly (acrylic) acid or carbomer) was gradually dispersed in distilled water under mild stirring (Remi, Mumbai) for $30 \mathrm{~min}$ and kept for two hours for the proper swelling of polymer.
TABLE 1: Formulation table for apple extract loaded silver nanoparticles based hydrogels.

\begin{tabular}{lcccc}
\hline \multirow{2}{*}{ S. number } & Ingredients & \multicolumn{3}{c}{ Formulations } \\
& & F1 & F2 & F3 \\
\hline$(1)$ & Apple AgNPs & $8 \mathrm{~mL}$ & $4 \mathrm{~mL}$ & $4 \mathrm{~mL}$ \\
$(2)$ & Carbopol-934 & $4 \%$ & $4 \%$ & $8 \%$ \\
$(3)$ & Glycerine & $2 \mathrm{~mL}$ & $2 \mathrm{~mL}$ & $2 \mathrm{~mL}$ \\
$(4)$ & Triethanolamine & $1 \mathrm{~mL}$ & $1 \mathrm{~mL}$ & $1 \mathrm{~mL}$ \\
$(5)$ & Distilled water & q.s. to & q.s. to & q.s. to \\
& & $100 \mathrm{~mL}$ & $100 \mathrm{~mL}$ & $100 \mathrm{~mL}$ \\
\hline
\end{tabular}

Glycerin was then added as viscosity enhancer and emollient. The glycerin-polymeric solution was then neutralized with triethanolamine to form a transparent gel as basic nature of triethanolamine helps in increasing the cross-linking of acidic polymer. Apple extract loaded silver nanoparticulate suspension (equivalent to $3-10 \%$ of apple extract) was then incorporated in hydrogel using slow mechanical mixing (Remi RQ121/D, Mumbai) for $10 \mathrm{~min}$ so as to avoid entry of air bubbles.

\subsubsection{Characterization of Apple Extract Loaded Silver Nanoparticles}

\section{(1) Characterization of Apple Extract}

Preliminary Screening for the Presence of Flavonoids and Polyphenols in Extract. The prepared apple extract was subjected to ultravoilet-visible spectrophotometry (Perkin Elmer, Waltham, MA) for detecting the presence of flavonoids. The extract was scanned in the region of $200 \mathrm{~nm}-800 \mathrm{~nm}$ against solvent mixture (MFW) as blank and peaks were obtained [16].

Few drops of dilute sodium hydroxide were added to $1 \mathrm{~mL}$ of apple extract to observe the yellow color which on further addition of few drops of dilute hydrochloric acid makes the solution colorless which confirms the presence of flavonoids.

Confirmatory Testing (Magnesium Ribbon Test) [17]. Magnesium ribbon test is known because of the use of magnesium ribbon in the testing of flavonoids. Concentrated hydrochloric acid and magnesium ribbon were added to $1 \mathrm{~mL}$ of apple extract which in turn gives pink-red color for the presence of flavonoids.

\section{(2) Characterization of Apple Extract Loaded Silver Nanoparticles}

Ultravoilet-Visible Spectrophotometry. The optical property of prepared AgNPs was analyzed via UV-visible absorption spectrophotometer with a deuterium and tungsten iodine lamp in range of $200-800 \mathrm{~nm}$ at room temperature (RT). UVvisible spectrophotometer monitors the formation of AgNPs with the color change. To analyze formation of AgNPs, 
samples were withdrawn with the help of pipette at different time intervals, that is, $5,10,15,20,30$, and 60 minutes [18].

Shape and Surface Morphology of Silver Nanoparticles. Scanning electron microscopic (SEM) analysis was done for analyzing particle shape and morphology. The shape and surface morphology of the silver nanoparticles was visualized by scanning electron microscopy (Cart Zeiss EV018). The samples were prepared by lightly sprinkling nanoparticles on double-sided adhesive tape on an aluminum stub. The stubs were then coated with gold to a thickness of 200 to $500 \AA$ under an argon atmosphere using a gold sputter module in a high vacuum evaporator. The samples were then randomly scanned and photomicrographs were taken at different magnifications with SEM [19].

Particle Size and Zeta Potential Measurement. Particle size was measured with the help of dynamic light scattering technique. For the determination of particle size, samples were prepared by tenfold dilution of $1 \mathrm{~mL}$ of the nanoparticulate suspension with distilled water. The analysis was carried out in triplicate. The average particle size was measured by photon correlation spectroscopy. Zeta potential was determined by the electrophoretic mobility of nanoparticles in U-type tube at $25^{\circ} \mathrm{C}$, using a zetasizer (3000HS Malvern Instruments, UK) [19].

\section{(3) Characterization of Apple Extract Loaded Silver Nanoparticles Based Hydrogels}

$p H$. $\mathrm{pH}$ of prepared hydrogel was measured by dissolving $1 \mathrm{gm}$ of hydrogel in $10 \mathrm{~mL}$ of distilled water. $\mathrm{pH}$ meter (Systronics, 361-micro pH meter) was used to evaluate the $\mathrm{pH}$ of hydrogel. The readings were taken in triplicate and the average $\mathrm{pH}$ was calculated.

Porosity Measurement. For porosity measurement, the solvent replacement technique was employed. Accurately weighed $1 \mathrm{gm}$ of dried hydrogels was immersed in absolute ethanol and soaked overnight. Afterwards, excess ethanol on the surface of hydrogels was blotted and weighed again [20]. The porosity can be calculated from the following equation.

$$
\text { Porosity }=\frac{(M 2-M 1)}{\rho V} .
$$

Here, $M 1$ and $M 2$ are the mass of hydrogel before and after the immersion in absolute ethanol, respectively; $\rho$ is the density of absolute ethanol and $V$ is the volume of the hydrogel.

Viscosity. To analyze the rheological properties, all the formulated gels were taken in beakers and placed beneath the spindle, and the spindle (RV-7) was rotated at $10 \mathrm{rpm}$ at room temperature $\left(25-27^{\circ} \mathrm{C}\right)$ in Brookfield viscometer.

Spreadability. The Spreadability measurements of the apple extract loaded silver nanoparticle gel were made in triplicate by using glass slide method. One gram per meter of gel was kept between the two slides. The preweighted plate was kept above the gel, and more weights were added on the plate until the gel stop spreading. Final cumulative weight and the total time taken by the gel to spread were measured and noted. Then total weight applied and mass of the gel were compared by the time.

$$
S=M \times \frac{L}{T}
$$

where $S$ = spreadability, $M=$ weight tide to upper slide, $L=$ length of glass slide, and $T=$ time taken to separate the slides completely from each other.

2.2.5. In Vitro Drug Diffusion Studies. The in vitro drug release was evaluated using Keshary-Chien (K-C) diffusion cell to evaluate the diffusion of nanoparticles across the dialysis membrane. The diffusion cells were thermoregulated with a water jacket at $37 \pm 2^{\circ} \mathrm{C}$. Dialysis membrane $70(\mathrm{Hi}-$ Media, Mumbai, India) having a pore size of $2.4 \mathrm{~nm}$ and a molecular weight cutoff between 12,000 and $14,000 \mathrm{Da}$ was used and mounted on K-C cells. The surface area of the release membrane was $3.14 \mathrm{~cm}^{2}$. Phosphate buffer saline (PBS; pH 6.8) was used as the receptor medium $(10 \mathrm{~mL})$ being stirred at $100 \mathrm{rpm} .0 .5 \mathrm{gm}$ of apple extract loaded silver nanoparticulate based hydrogel (equivalent to 3-10\% of apple extract) was placed in the donor compartment. During the experiments, the solution in receptor side was maintained at $37 \pm 0.5^{\circ} \mathrm{C}$. At predetermined time intervals, $5 \mathrm{~mL}$ of the samples was withdrawn from the receiver compartment and replaced by the same volume of freshly prepared PBS $(\mathrm{pH}$ 6.8). The withdrawn samples were analyzed by the UV-visible spectrophotometer at $420 \mathrm{~nm} \mathrm{[21].}$

2.2.6. Ex Vivo Skin Permeation Studies. The ex vivo drug release studies were carried out with the help of $\mathrm{K}$-C diffusion cell. Rat abdominal skin was used to study permeation. The subcutaneous tissue was removed surgically and the dermis side was wiped with isopropyl alcohol to remove adhering fat. The cleaned skin was washed with distilled water and stored at $-18^{\circ} \mathrm{C}$ until further use. The skin was mounted between the donor and receiver compartments of the $\mathrm{K}-\mathrm{C}$ cell where the stratum corneum side was facing the donor compartment and the dermal side was facing the receiver compartment. One gram (equivalent to 3-10\% apple extract) of each gel was placed in a donor compartment. The receptor compartment was filled with $10 \mathrm{~mL}$ PBS $(\mathrm{pH}$ 6.8 ), thermoregulated at $37^{\circ} \mathrm{C}$, and magnetically stirred at $400 \mathrm{rpm}$. Two milliliters of receptor fluid was withdrawn at an interval of $1,2,3,5,7,12,18$, and $24 \mathrm{~h}$. An equal volume of PBS was simultaneously added to the receptor compartment after each sampling to maintain sink conditions. Each sample was filtered and then determined for apple extract content by UV spectrophotometer at $420 \mathrm{~nm}$. The concentrations of all the formulations in withdrawn samples were calculated and then the percent drug release was determined [22].

2.2.7. Antioxidant Activity of Silver Nanoparticulate Hydrogel (DPPH Radical Scavenging Assay). The antioxidant activity 


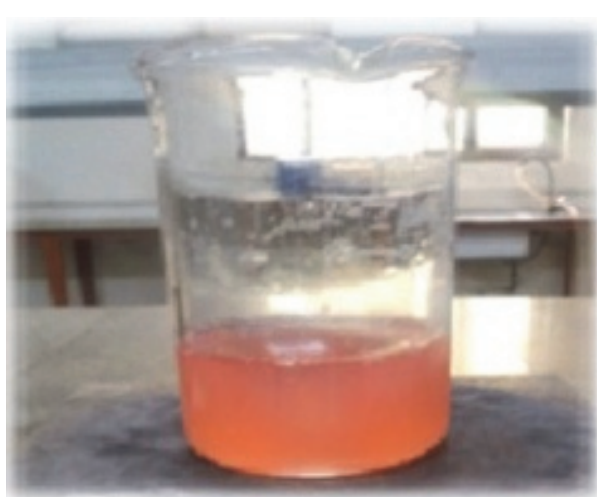

(a)

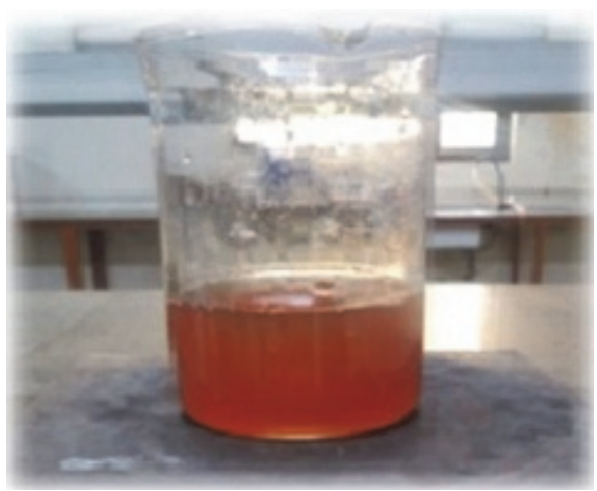

(b)

FIgURE 1: Formation of silver nanoparticles. (a) Color before initiation of reduction of silver ions; (b) color change after reduction.

was characterized utilizing DPPH (2,2-diphenyl-2-picrylhydrazyl hydrate) assay. A stock solution of DPPH in methanol was prepared. $1 \mathrm{~mL}$ of this stock solution was added to $3 \mathrm{~mL}$ of hydrogel solution (1 gm of prepared hydrogel in $10 \mathrm{~mL}$ of distilled water). The mixture was shaken vigorously and allowed to stand at room temperature for $30 \mathrm{~min}$. Then the absorbance was measured at $517 \mathrm{~nm}$ by using a UV-visible spectrophotometer. Antioxidant activity was estimated by calculating the $\%$ inhibition by following formula [23]:

DPPH scavenging effect (\%)

$$
\begin{aligned}
= & \frac{(\text { control absorbance }- \text { sample absorbance })}{\text { control absorbance }} \\
& \times 100 .
\end{aligned}
$$

2.2.8. Antimicrobial Activity of Silver Nanoparticulate Hydrogel. Antimicrobial activity was performed using welldiffusion technique employing agar and nutrient broth as media. Media was constituted by mixing agar and nutrient broth and then autoclaved at $121^{\circ} \mathrm{C}$ at $15 \mathrm{lbsi}$ for $60 \mathrm{~min}$ for sterilization. Sterilized liquid media were then poured into two different petri plates and inoculated with E. coli and $S$. aureus, respectively. The petri plates were kept for 5 min till solidification is complete. The entire work was carried out in laminar air flow unit. Sterilized cork borer was used to create well of $1 \mathrm{~cm}$ diameter in the solidified media. Samples were poured in the well of prepared petri plates and then incubated at $37 \pm 5^{\circ} \mathrm{C}$ for $24 \mathrm{~h}$ for inhibition to the growth of E. coli and S. aureus [24].

\section{Results and Discussion}

Apple extract was successfully prepared using MFW solution as explained in literature [14]. Extract obtained by the process was found to be pinkish red in color; the extract was further screened for the presence of flavonoids and phenols by preliminary screening and confirmatory testing. The phytochemical analysis of apple extract confirms the presence of phenols and flavonoids.

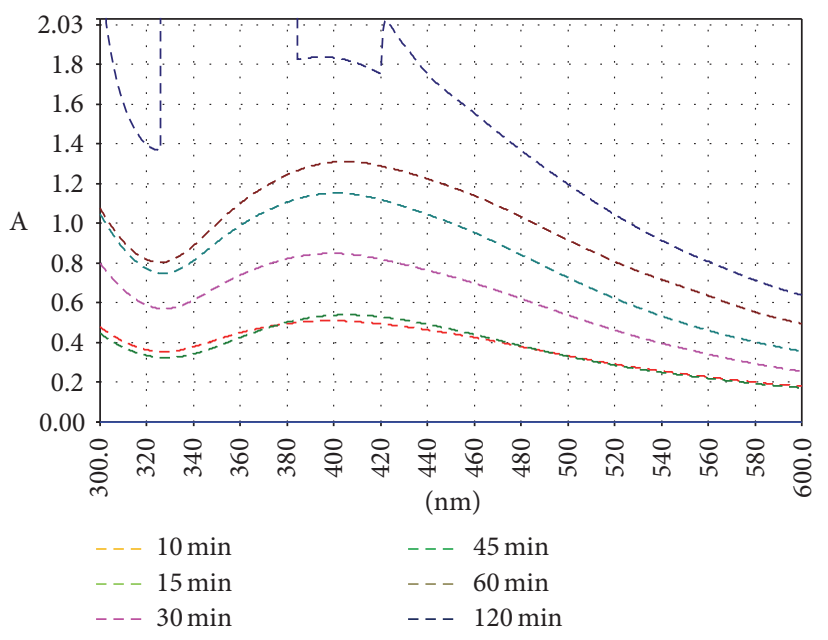

FIGURE 2: UV-visible spectra for apple extract loaded silver nanoparticles.

Silver nanoparticles prepared from apple extract showed the color change after 120 minutes of preparation giving the evidence for the reduction of silver ions and, eventually, formation of silver nanoparticles. The color change of the solution is clearly depicted in Figures 1(a) and 1(b).

The color change was recorded by visual observation in beaker which contains silver nitrate solution with apple extract. The color of AgNPS apple extract solution changes from colorless to light brown after $5 \mathrm{~min}$ and eventually to dark brown as shown in Figures 1(a) and 1(b). This color change indicates formation of AgNPs in solution [25, 26]. The synthesis of AgNPs was furthermore confirmed by UVvisible spectroscopy and scanning electron microscopy [24]. The UV-Vis spectrum of silver nanoparticles was recorded as a function of a reaction time. Aliquots of samples were withdrawn at different time intervals, that is, 10, 15, 30, 45, 60, and $120 \mathrm{~min}$, to monitor the bioreduction of $\mathrm{Ag}^{+}$ ions. The graph obtained by UV spectrophotometer contains significant bell shaped peak indicating the formation of silver nanoparticles as shown in Figure 2.

Figure 2 shows UV-visible absorption spectrum of synthesized AgNPs. AgNPs have free electrons which give 

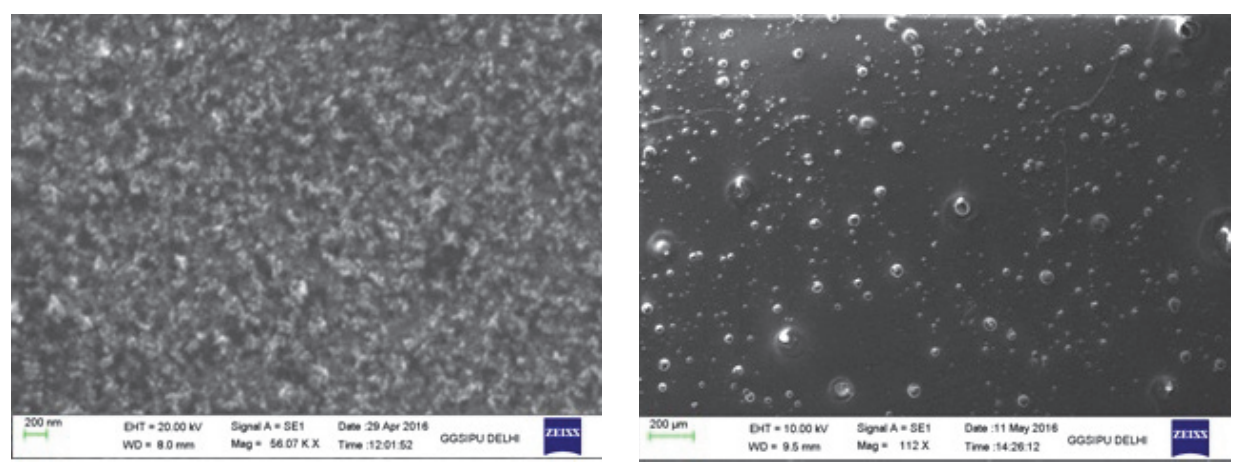

FIGURE 3: Scanning electron microscopic images of apple extract loaded silver nanoparticles.

TABLE 2: Evaluation parameters of apple extract loaded silver nanoparticles based hydrogels.

\begin{tabular}{lcccc}
\hline S. number & Parameters & F1 & F2 & F3 \\
\hline$(1)$ & $\mathrm{pH}$ & $6.11 \pm 0.1$ & $6.36 \pm 0.15$ & $6.66 \pm 0.2$ \\
$(2)$ & Viscosity & $40000 \mathrm{cps}$ & $42000 \mathrm{cps}$ & $43000 \mathrm{cps}$ \\
$(3)$ & Spreadability & $4.83 \pm 0.3 \mathrm{~g} \cdot \mathrm{cm} / \mathrm{sec}$ & $5.56 \pm 0.15 \mathrm{~g} \cdot \mathrm{cm} / \mathrm{sec}$ & $5.63 \pm 0.15 \mathrm{~g} \cdot \mathrm{cm} / \mathrm{sec}$ \\
$(4)$ & Porosity & $55.4 \%$ & $61.2 \%$ & $63.9 \%$ \\
\hline
\end{tabular}

surface plasmon resonance (SPR) absorption band. This SPR absorption band may be attributed to combined variation of electrons of AgNPs in resonance with light wave. It is very much familiar that silver nanoparticles in nanorange show absorption at the wavelength from $390 \mathrm{~nm}$ to $420 \mathrm{~nm}$ due to Mie scattering. Therefore, a broad absorption band was observed in the range of $400 \mathrm{~nm}-440 \mathrm{~nm}$ which is the characteristic of Mie scattering $[27,28]$. No other peak was recorded in spectrum which confirms that synthesized nanoparticles are silver particles only. SEM technique was employed to evaluate AgNPs size, shape, and surface morphology. The average size of the particles was found to be below $200 \mathrm{~nm}$ and the particles formed were spherical in shape, as shown in Figure 3.

From Figure 3, it can be illustrated that morphology of AgNPs is spherical and particles are well dispersed without any aggregation. The particle size of the silver nanoparticles was found to be in the range of $100 \mathrm{~nm}$ indicating best suitability for topical delivery as particles on nanoscale can easily permeate through skin. The zeta potential was found to be very negative on higher scale revealing good stability of AgNps in dispersion form. The prepared hydrogel was evaluated for $\mathrm{pH}$, viscosity, spreadability, and porosity. The $\mathrm{pH}$ of all formulated hydrogel was found in the range of 5.5-7.5, which mimics the $\mathrm{pH}$ of skin; therefore, formulation shows no sign of irritation on skin. The results of rheological studies, namely, viscosity and spreadability of the formulation, were found to be $42000 \mathrm{cps}$ and $5.56 \pm 0.15 \mathrm{~g} \cdot \mathrm{cm} / \mathrm{sec}$, respectively, which clearly signify that the hydrogel is easy to spread on skin. The results of all the three batches formulated are mentioned in Table 2. Furthermore, hydrogel formulations were then subject to in vitro drug release to compute the rate and extent of drug release.

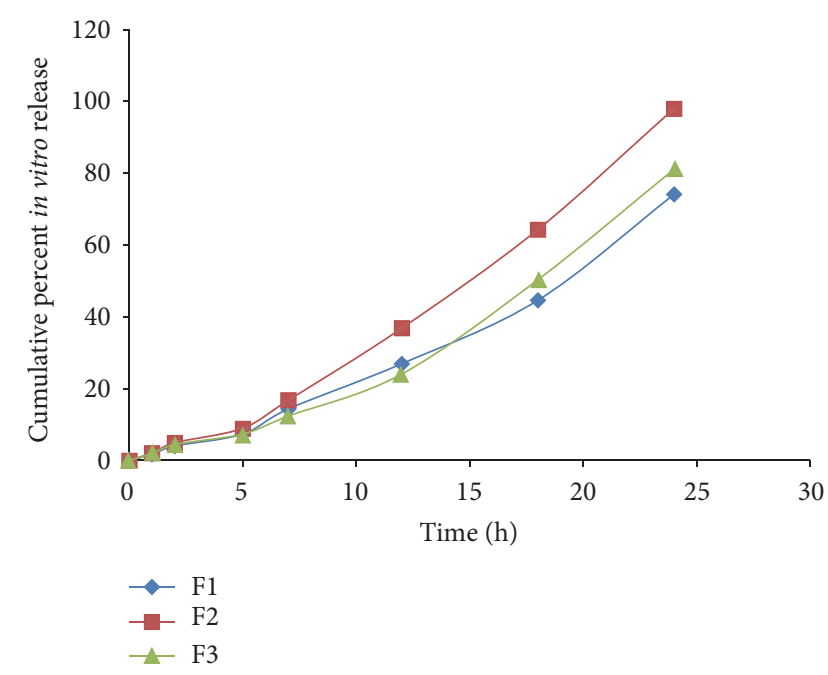

FIGURE 4: Cumulative percent in vitro release of apple extract loaded silver nanoparticles.

3.1. In-Vitro Release. The results of in vitro drug release of all three formulations were in the range of $74.1 \% \pm 0.28$ to $98.01 \% \pm 0.37$ up to $24 \mathrm{~h}$ concluding the maximum release was shown by F2 hydrogel formulation as shown in Figure 4. On the basis of results in Table 2, optimized hydrogel formulation was selected. Primary focus was laid on particle size as this will play significant role in nanoparticle permeation from skin. The smaller the particle size is, the easier the permeation will be. Additionally, to confirm the permeation of nanoparticle across the membrane, rat abdominal skin was selected. F2 hydrogel formulation displayed the maximum release. 

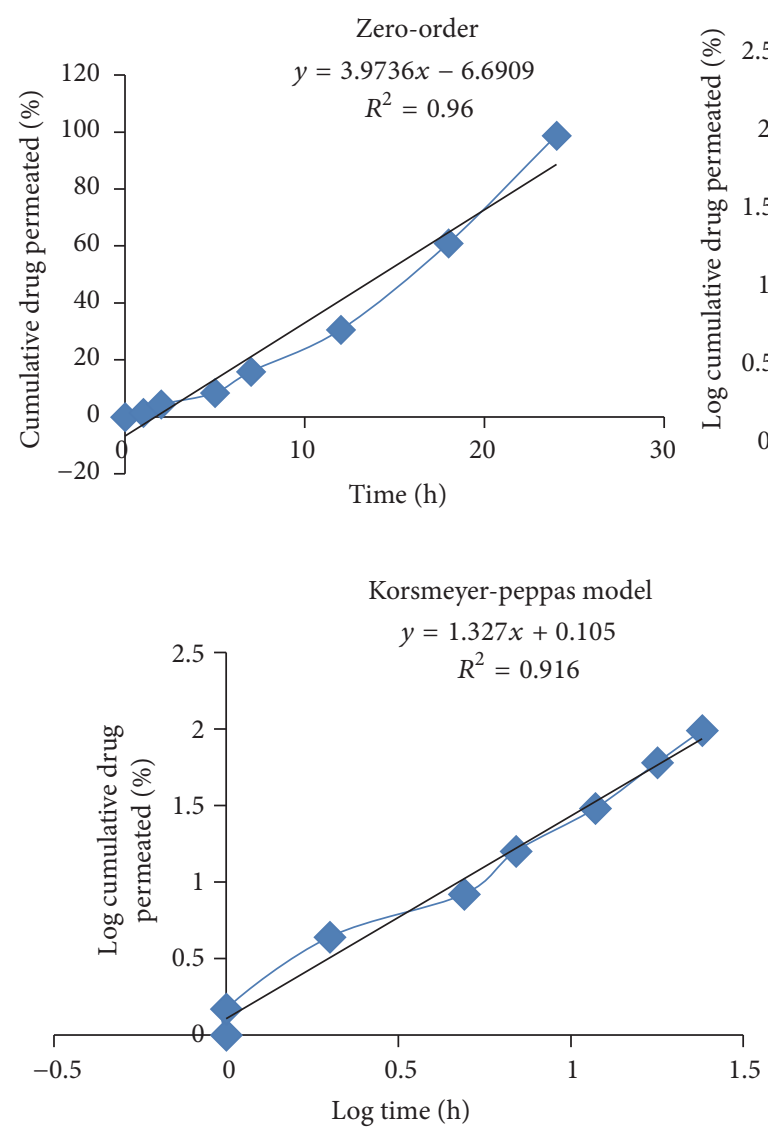
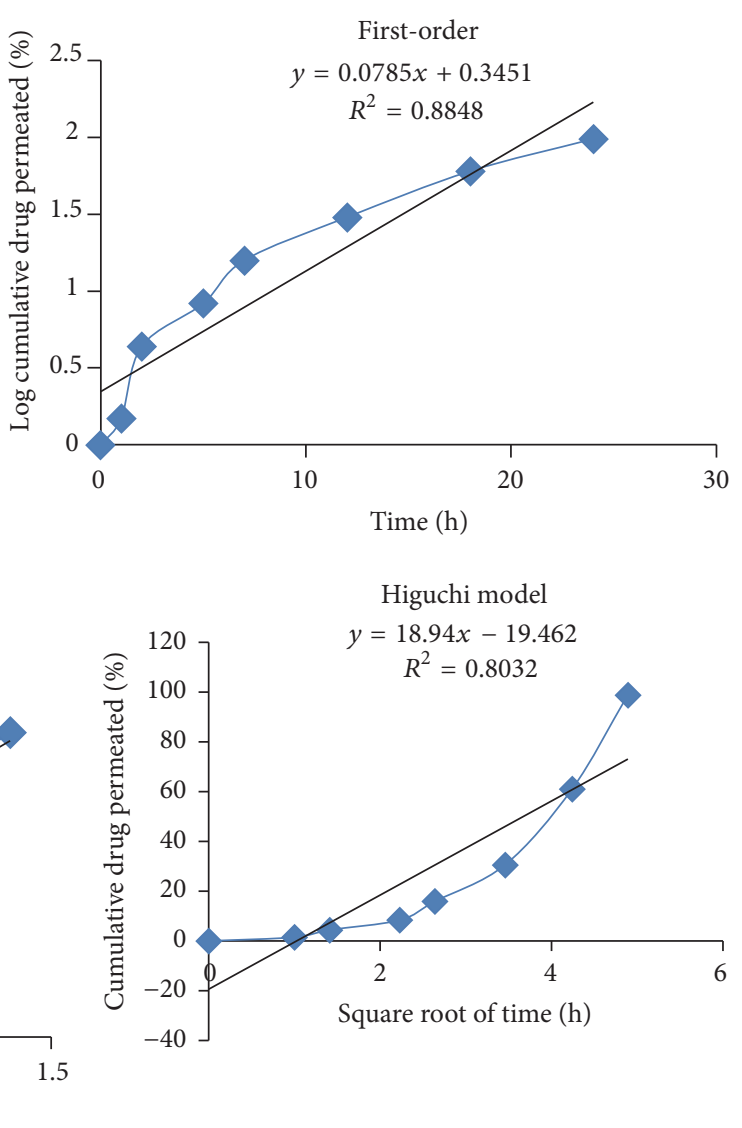

FIGURE 5: Ex vivo drug permeation kinetics of apple extract loaded silver nanoparticles based hydrogels.

TABLE 3: Release kinetics and permeation parameters for apple extract loaded silver nanoparticles based hydrogels.

\begin{tabular}{lccccccccc}
\hline & \multicolumn{1}{c}{ Apple extract loaded AgNPs based hydrogel (F2) } \\
Zero-order & 1st-order equation & \multicolumn{2}{c}{$\begin{array}{c}\text { Korsmeyer-Peppas } \\
\text { equation }\end{array}$} & Higuchi equation & $\begin{array}{c}\text { Flux } \\
\left(\mu \mathrm{g} / \mathrm{cm}^{2} / \mathrm{h}\right)\end{array}$ & $\begin{array}{c}\text { Permeability coefficient } \\
(P)(\mathrm{cm} / \mathrm{h})\end{array}$ \\
\hline$k$ & $R^{2}$ & $k$ & $R^{2}$ & $n$ & $R^{2}$ & $k$ & $R^{2}$ & Lag time $(\mathrm{h})$ \\
\hline 3.973 & 0.96 & 0.078 & 0.884 & 0.105 & 0.916 & 19.46 & 0.803 & 0.0124 & 0.315 \\
\hline
\end{tabular}

3.2. Ex Vivo Permeation Studies and Release Kinetics. Ex vivo permeation studies were only conducted for batch F2 as smaller particle size and maximum in vitro release was shown by this formulation. Cumulative percent permeation was found to be $98.81 \% \pm 0.24$ up to $24 \mathrm{~h}$. The permeation studies were best explained by zero-order kinetics $\left(R^{2}=\right.$ $0.96)$, followed by first-order kinetics $\left(R^{2}=0.884\right)$ and Higuchi equation $\left(R^{2}=0.803\right)$. Ex vivo permeation kinetics through zero-order, first-order, Korsmeyer-Peppas model, and Higuchi model have been explained in Figure 5. The values of $R^{2}$ and $k$ for all release kinetics models are tabulated in Table 3. Zero-order process is a constant rate process that is independent of drug concentration [29]. This perfectly highlights apple extract silver nanoparticles loaded hydrogels as sustained release dosage form. Permeation parameters like flux, permeability coefficient, and lag time are summarized in Table 3.
3.3. Antioxidant Activity of Apple Extract Loaded Silver Nanoparticles Loaded Hydrogels. DPPH radical scavenging assay was investigated for the evaluation of antioxidant potential of the prepared hydrogel formulations. The purple solution containing DPPH turns yellow on addition of formulation, which indicates the scavenging of free radicals and presence of antioxidant activity [30]. The results are compiled in Table 4 and showed that the ratio of AgNPs with carbopol $(2: 1)$, that is, $\mathrm{F} 1$, demonstrated maximum inhibition with a value of $75.16 \pm 0.04$. At the same time, the value differs with other ratios, namely, AgNPs with carbopol (1:1) F2 and AgNPs with carbopol (1:2) F3. Thus, it can be concluded that maximum concentration of apple extract revealed maximum percent inhibition.

3.4. Antimicrobial Activity of Silver Nanoparticulate Hydrogel. Apple extract loaded silver nanoparticles based hydrogels 


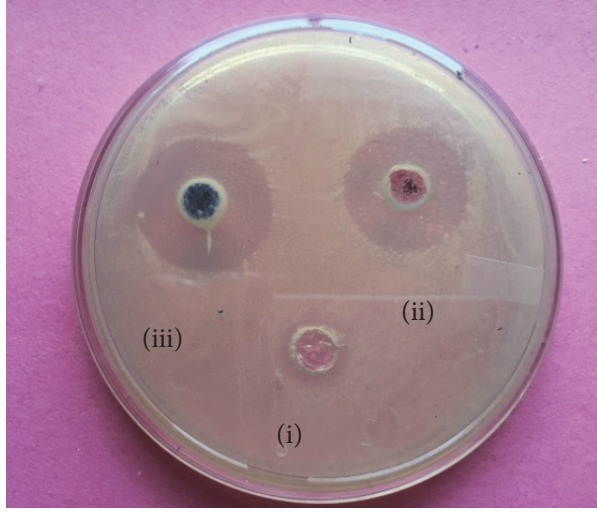

(a)

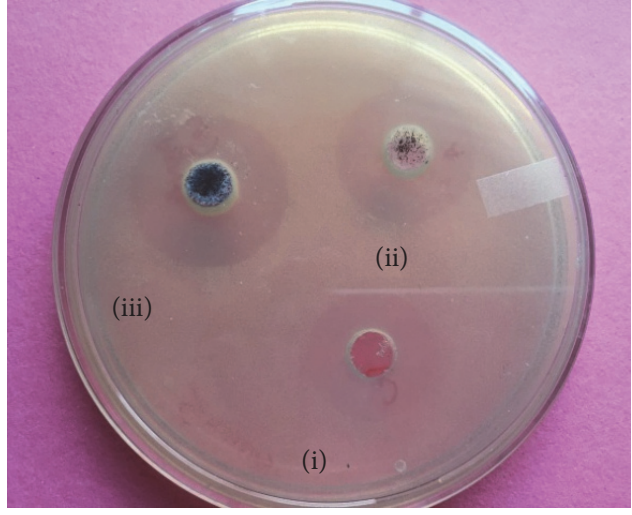

(b)

FIgURE 6: Antibacterial activity of silver nanoparticles (a) inhibition against E. coli and (b) inhibition against S. aureus. (i) Plain extract containing hydrogel, (ii) silver nanoparticles containing apple extract, and (iii) apple AgNPs loaded hydrogel.

TABLE 4: Antioxidant activity of apple extract silver nanoparticles loaded hydrogels (DPPH radical scavenging assay).

\begin{tabular}{lcc}
\hline S. number & Formulations & Percent DPPH scavenging effect \\
\hline$(1)$ & F1 & $75.16 \% \pm 0.04$ \\
$(2)$ & F2 & $69.22 \% \pm 0.02$ \\
$(3)$ & F3 & $68.18 \% \pm 0.03$ \\
\hline
\end{tabular}

showed higher antimicrobial properties against the bacterial species of E. coli and $S$. aureus. Well-diffusion method was opted to evaluate the antibacterial activity. The inhibitory action of silver compounds may be attributed to the strong interaction of silver with thiol groups present in key respiratory enzymes in bacteria [31].

The samples shows good zone of inhibition. Figures 6(a) and 6(b) show the zone of inhibition obtained against $E$. coli and $S$. aureus, respectively. A good inhibition was shown by silver nanoparticles based hydrogel contrary to plain hydrogel containing apple extract where no zone of inhibition was seen against $E$. coli as well as for $S$. aureus.

\section{Conclusion}

In the present research, green synthesis of apple extract loaded Ag-NPs was successfully achieved by treatment of silver nitrate with extract of Malus domestica (apple). This technique revealed that the apple extracts can be used as an effective stabilizing reducing and capping agent for the synthesis of AgNPs. This method of reduction utilized here is very simple, easy to perform, inexpensive, eco-friendly, and superior substitute to chemical synthesis. The finally fashioned AgNPs based hydrogels were highly stable formulations, showing strong antibacterial and antioxidant activity.

\section{Competing Interests}

The authors report no competing interests.

\section{Acknowledgments}

The authors wish to thank Founder President Dr. Ashok K. Chauhan, Amity University, for their kind support during research. The authors also like to acknowledge Professor A. K Narula Director C.E.P.S, Guru Gobind Singh Indraprasth University, for providing facility of SEM.

\section{References}

[1] S. Raj, S. Jose, U. S. Sumod, and M. Sabitha, "Nanotechnology in cosmetics: opportunities and challenges," Journal of Pharmacy and Bioallied Sciences, vol. 4, no. 3, pp. 186-193, 2012.

[2] U. Nagaich, "Nanocosmeceuticals: a boon to personal care products," Journal of Advanced Pharmaceutical Technology and Research, vol. 7, article 1, 2016.

[3] D. Kumar, N. Jain, N. Gulati, and U. Nagaich, "Nanoparticles laden in situ gelling system for ocular drug targeting," Journal of Advanced Pharmaceutical Technology and Research, vol. 4, no. 1, pp. 9-17, 2013.

[4] S. Ghosh, S. Patil, M. Ahire et al., "Synthesis of silver nanoparticles using Dioscorea bulbifera tuber extract and evaluation of its synergistic potential in combination with antimicrobial agents," International Journal of Nanomedicine, vol. 7, pp. 483-496, 2012.

[5] L. Ge, Q. Li, M. Wang, J. Ouyang, X. Li, and M. M. Q. Xing, "Nanosilver particles in medical applications: synthesis, performance, and toxicity," International Journal of Nanomedicine, vol. 9, no. 1, pp. 2399-2407, 2014.

[6] S. Iravani, H. Korbekandi, S. V. Mirmohammadi, and B. Zolfaghari, "Synthesis of silver nanoparticles: chemical, physical and biological methods," Research in Pharmaceutical Sciences, vol. 9, no. 6, pp. 385-406, 2014.

[7] V. Palermo, F. Mattivi, R. Silvestri, G. La Regina, C. Falcone, and C. Mazzoni, "Apple can act as anti-aging on yeast cells," Oxidative Medicine and Cellular Longevity, vol. 2012, Article ID 491759, 8 pages, 2012.

[8] S. Jadoon, S. Karim, M. H. H. B. Asad et al., "Anti-aging potential of phytoextract loaded-pharmaceutical creams for human skin cell longetivity," Oxidative Medicine and Cellular Longevity, vol. 2015, Article ID 709628, 17 pages, 2015. 
[9] A. Rasul and N. Akhtar, "Formulation and in vivo evaluation for anti-aging effects of an emulsion containing basil extract using non-invasive biophysical techniques," Journal of Faculty of Pharmacy, Tehran University of Medical Sciences, vol. 19, no. 5, pp. 344-350, 2011.

[10] D. L. Bissett, R. Chatterjee, and D. P. Hannon, "Photoprotective effect of super-oxide scavenging antioxidants against ultraviolet radiation-induced chronic skin damage in the hairless mouse," Photodermatology Photoimmunology and Photomedicine, vol. 7, no. 2, pp. 56-62, 1990.

[11] R. Ganceviciene, A. I. Liakou, A. Theodoridis, E. Makrantonaki, and C. C. Zouboulis, "Skin anti-aging strategies," DermatoEndocrinology, vol. 4, no. 3, pp. 308-319, 2012.

[12] K. Rahman, "Studies on free radicals, antioxidants, and cofactors," Clinical Interventions in Aging, vol. 2, no. 2, pp. 219-236, 2007.

[13] D. A. Hyson, "A comprehensive review of apples and apple components and their relationship to human health," Advances in Nutrition, vol. 2, no. 5, pp. 408-420, 2011.

[14] N. Akhtar, H. M. S. Khan, F. Gulfishan Rasool, M. Ahmad, and T. Saeed, "Formulation and in vitro evaluation of a cosmetic emulsion containing apple juice extract," Asian Journal of Chemistry, vol. 22, pp. 7235-7242, 2010.

[15] R. R. Banala, V. B. Nagati, and P. R. Karnati, "Green synthesis and characterization of Carica papaya leaf extract coated silver nanoparticles through X-ray diffraction, electron microscopy and evaluation of bactericidal properties," Saudi Journal of Biological Sciences, vol. 22, no. 5, pp. 637-644, 2015.

[16] G. Giomaro, A. Karioti, A. R. Bilia et al., "Polyphenols profile and antioxidant activity of skin and pulp of a rare apple from Marche region (Italy)," Chemistry Central Journal, vol. 8, no. 1, article 45, 2014.

[17] P. S. Pavithra, N. Sreevidya, and R. S. Verma, "Antibacterial and antioxidant activity of methanol extract of Evolvulus nummularius," Indian Journal of Pharmacology, vol. 41, no. 5, pp. 233-236, 2009.

[18] G. Marslin, R. K. Selvakesavan, G. Franklin, B. Sarmento, and A. C. P. Dias, "Antimicrobial activity of cream incorporated with silver nanoparticles biosynthesized from Withania somnifera," International Journal of Nanomedicine, vol. 10, pp. 5955-5963, 2015.

[19] N. Gulati, U. Nagaich, and S. A. Saraf, "Intranasal delivery of chitosan nanoparticles for migraine therapy," Scientia Pharmaceutica, vol. 81, no. 3, pp. 843-854, 2013.

[20] N. Vishal Gupta and H. G. Shivakumar, "Preparation and characterization of superporous hydrogels as gastroretentive drug delivery system for rosiglitazone maleate," DARU, Journal of Pharmaceutical Sciences, vol. 18, no. 3, pp. 200-210, 2010.

[21] A. Chatterjee, B. B. Bhowmik, and Y. S. Thakur, "Formulation, in vitro and in vivo pharmacokinetics of anti-HIV vaginal bioadhesive gel," Journal of Young Pharmacists, vol. 3, no. 2, pp. 83-89, 2011.

[22] I. Özcan, E. Azizoğlu, T. Şenyiğit, M. Özyazici, and Ö. Özer, "Enhanced dermal delivery of diflucortolone valerate using lecithin/chitosan nanoparticles: in-vitro and in-vivo evaluations," International Journal of Nanomedicine, vol. 8, pp. 461475, 2013.

[23] M. Biswas, P. K. Haldar, and A. K. Ghosh, "Antioxidant and freeradical-scavenging effects of fruits of Dregea volubilis," Journal of Natural Science, Biology and Medicine, vol. 1, no. 1, pp. 29-34, 2010.
[24] T. N. V. K. V. Prasad and E. K. Elumalai, "Biofabrication of Ag nanoparticles using Moringa oleifera leaf extract and their antimicrobial activity," Asian Pacific Journal of Tropical Biomedicine, vol. 1, no. 6, pp. 439-442, 2011.

[25] R. Geethalakshmi and D. V. L. Sarada, "Gold and silver nanoparticles from Trianthema decandra: synthesis, characterization, and antimicrobial properties," International Journal of Nanomedicine, vol. 7, pp. 5375-5384, 2012.

[26] K. S. Mukunthan, E. K. Elumalai, T. N. Patel, and V. R. Murty, "Catharanthus roseus: a natural source for the synthesis of silver nanoparticles," Asian Pacific Journal of Tropical Biomedicine, vol. 1, no. 4, pp. 270-274, 2011.

[27] R. Singh, P. Wagh, S. Wadhwani et al., "Synthesis, optimization, and characterization of silver nanoparticles from Acinetobacter calcoaceticus and their enhanced antibacterial activity when combined with antibiotics," International Journal of Nanomedicine, vol. 8, pp. 4277-4290, 2013.

[28] P. Balashanmugam and P. T. Kalaichelvan, "Biosynthesis characterization of silver nanoparticles using Cassia roxburghii DC. aqueous extract, and coated on cotton cloth for effective antibacterial activity," International Journal of Nanomedicine, vol. 10, supplement 1, pp. 87-97, 2015.

[29] V. Senthil, R. S. Kumar, C. V. V. Nagaraju, N. Jawahar, G. N. K. Ganesh, and K. Gowthamarajan, "Design and development of hydrogel nanoparticles for mercaptopurine," Journal of Advanced Pharmaceutical Technology \& Research, vol. 1, no. 3, pp. 334-337, 2010.

[30] S. Jelodarian, A. Haghir Ebrahimabadi, A. Khalighi, and H. Batooli, "Evaluation of antioxidant activity of Malus domestica fruit extract from Kashan area," Avicenna Journal of Phytomedicine, vol. 2, no. 3, pp. 139-145, 2012.

[31] K. Singh, M. Panghal, S. Kadyan, U. Chaudhary, and J. P. Yadav, "Antibacterial activity of synthesized silver nanoparticles from Tinospora cordifolia against multi drug resistant strains of Pseudomonas aeruginosa isolated from burn patients," Journal of Nanomedicine and Nanotechnology, vol. 5, article 192, 2014. 

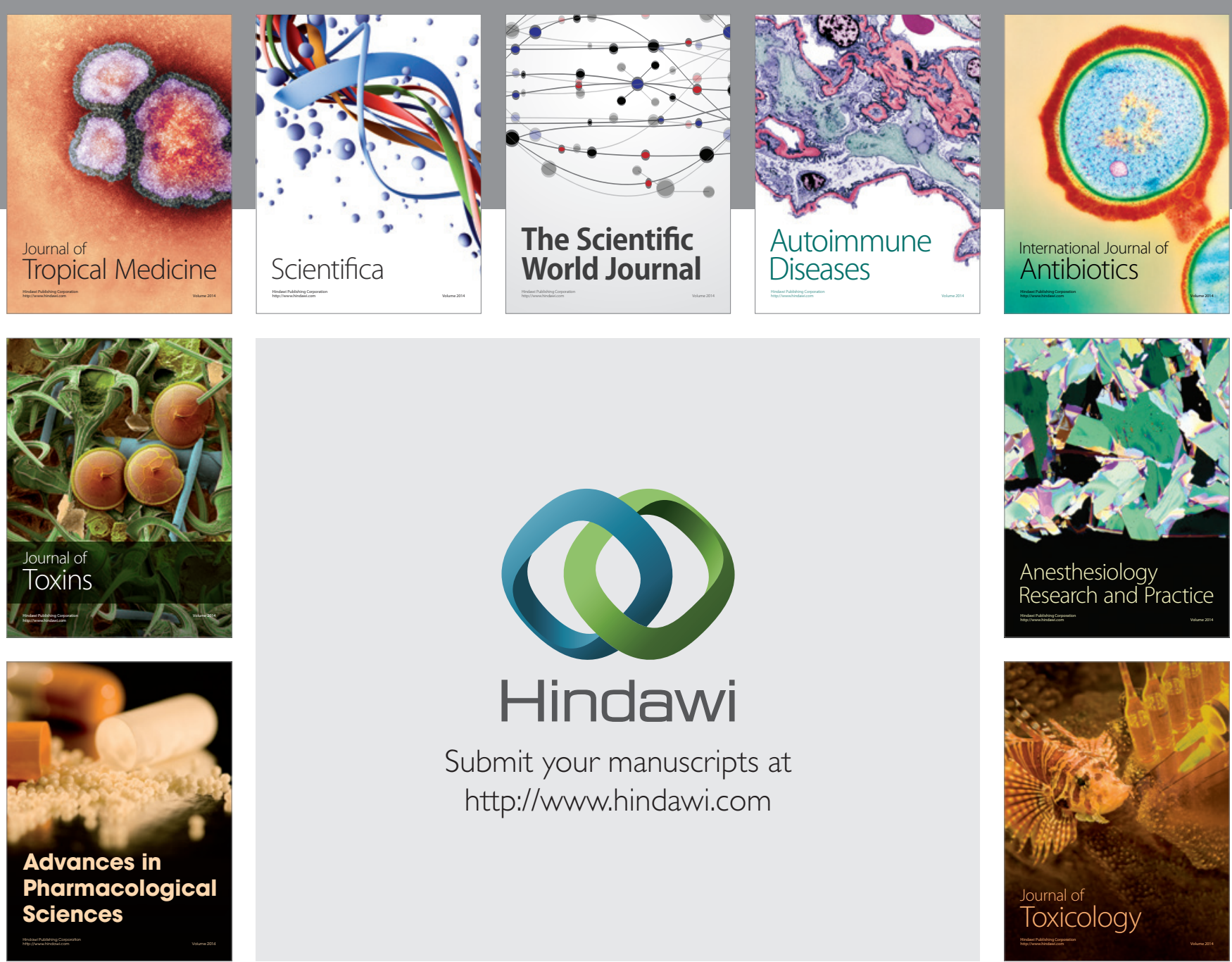

\section{Hindawi}

Submit your manuscripts at

http://www.hindawi.com
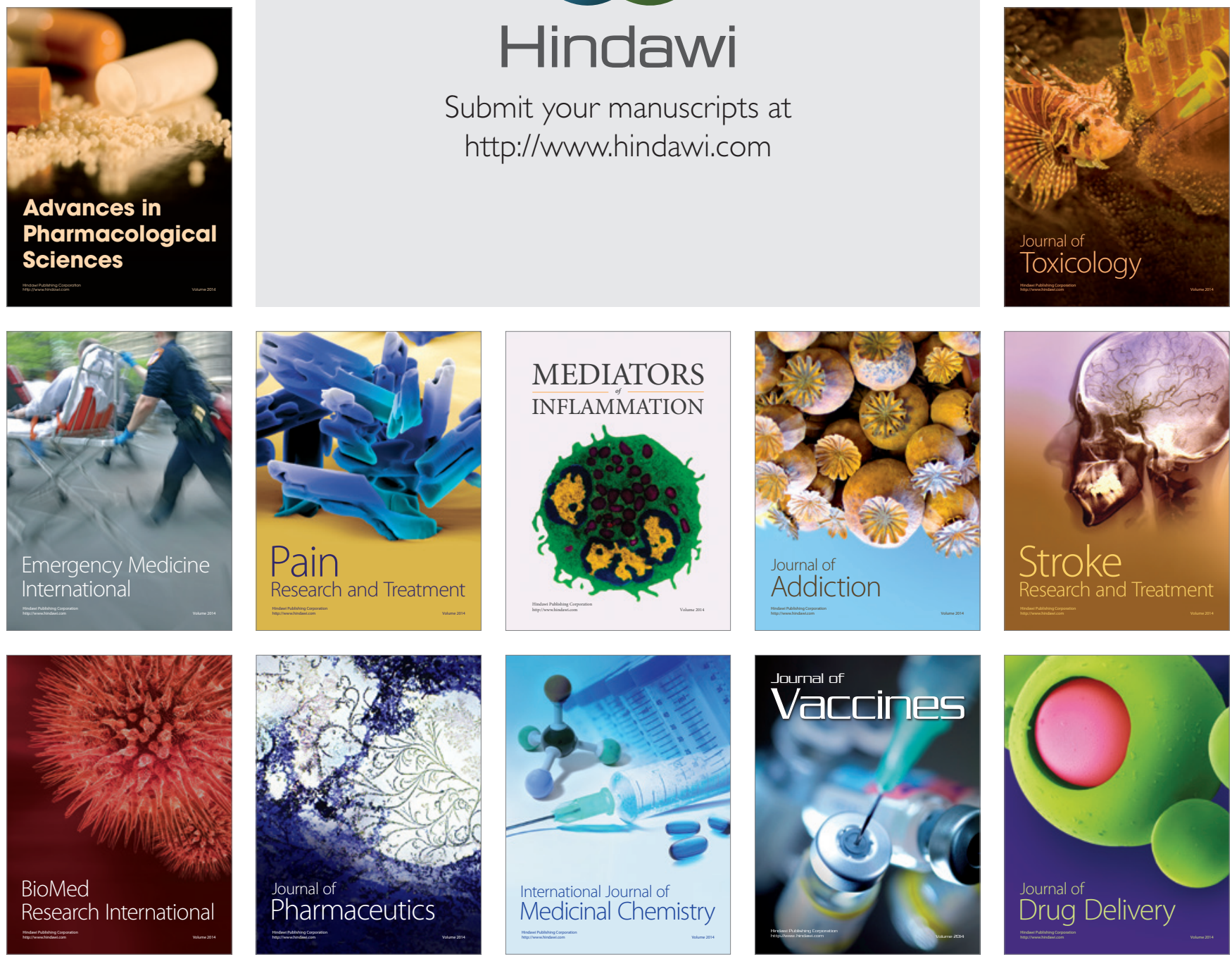